\title{
Ultrastructural Defects in Developing Enamel of Diabetic Mice
}

\author{
M. Atar*, Ph. Verry**, D.R. Atar-Zwillenberg*, and U.M. Spornitz* \\ *Institute of Anatomy of the University of Basel, Division of Electron Microscopy, 4056 Basel, \\ Switzerland \\ **Hoffmann-La Roche Ltd., Pharmaceuticals Division, Metabolic Preclinical Research, Vascular \\ and Metabolic Diseases, 4070 Basel, Switzerland
}

\section{Background}

Diabetes is one of the most widespread diseases in the world. Leading to microangiopathy it affects all developing organs requiring a strong blood supply. It was the goal of this study to provide ultrastructural evidence of possible effects of diabetes on the developing enamel by electron microscopy.[1]

\section{$\underline{\text { Methods }}$}

We investigated 6 different diabetic rodents, four of which expressed a genetic obesity resulting in diabetes, one type developed diabetes induced by a diet dependent obesity, and one type with genetic diabetes received antidiabetic medication. Following decapitation we macerated the animal heads, polished and cauterized the teeth. We examined the samples under the scanning electron microscope and thereby compared apical diabetic enamel with coronal control regions of the same tooth as well as apical regions of diabetic and control teeth.[2]

\section{$\underline{\text { Results }}$}

The electron micrographs showed severe defects in the enamel ultrastructure of all regions developing under the influence of diabetes. Particularly in the prism arrangement dramatic alterations are visible. We found varying degrees of the damage within the 6 different diabetic animal types, such as irregular cristallite deposition and prism perforations in genetically obese animals compared to less disordered prism structures in diet dependent obesity. Antidiabetic medication resulted in normal enamel structure.[3]

\section{Discussion}

Our work clearly demonstrates the destructive effects of diabetes on developing enamel in quality and quantity. We suggest that both the juvenile diabetes type I (in infants) and the adult diabetes type II (in pregnant mothers) may affect the normal development of teeth. Our findings will hopefully contribute to the future prevention and therapy of dental defects caused by diabetes.[4]

\section{$\underline{\text { References }}$}

[1] M.E. Cooper et al. (2001). Am. J. Hypertens. 14: 475-486.

[2] T. Martin (1997). In: K.W. Alt and J.C. Türp (eds.). Quintessenz, Berlin, Germany. 401-422.

[3] J.G. Noren (1984). Acta Odontol. Scand. 42(3): 153-156.

[4] This research was supported by the GABA International Ltd., Münchenstein, Switzerland, and by a personal research grant of the Swiss Dental Society Research Foundation, Bern, Switzerland 


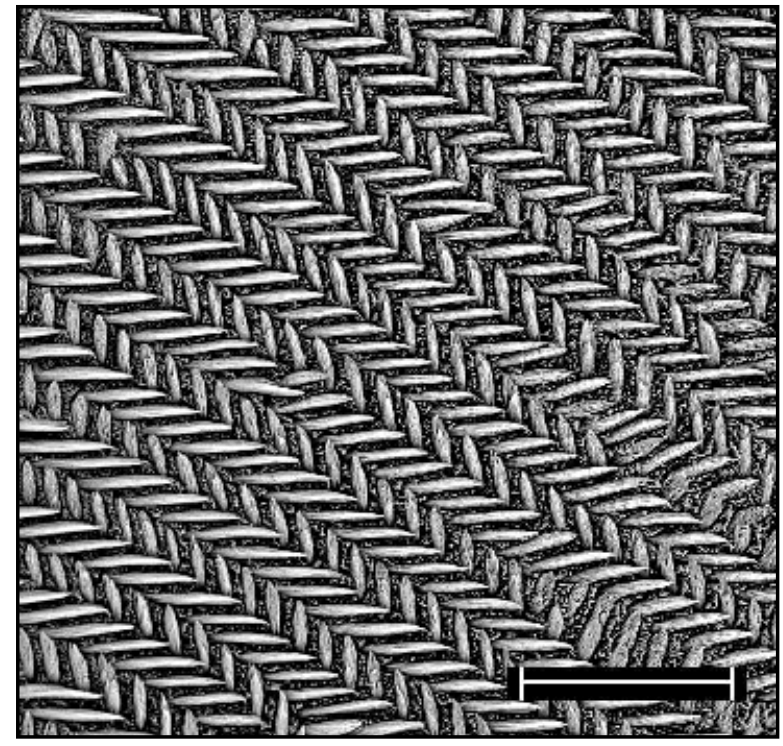

Fig. 1 Normal enamel structure of a coronal control region (bar $20 \mu \mathrm{m}$ )

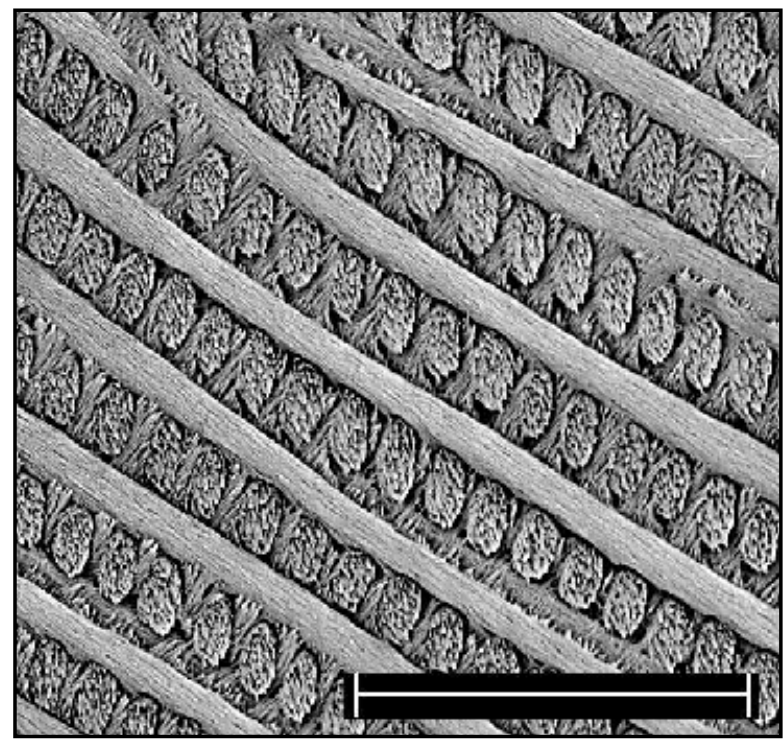

Fig. 3 Normal enamel structure of an apical region of a non diabetic control animal (bar 20 $\mu \mathrm{m})$

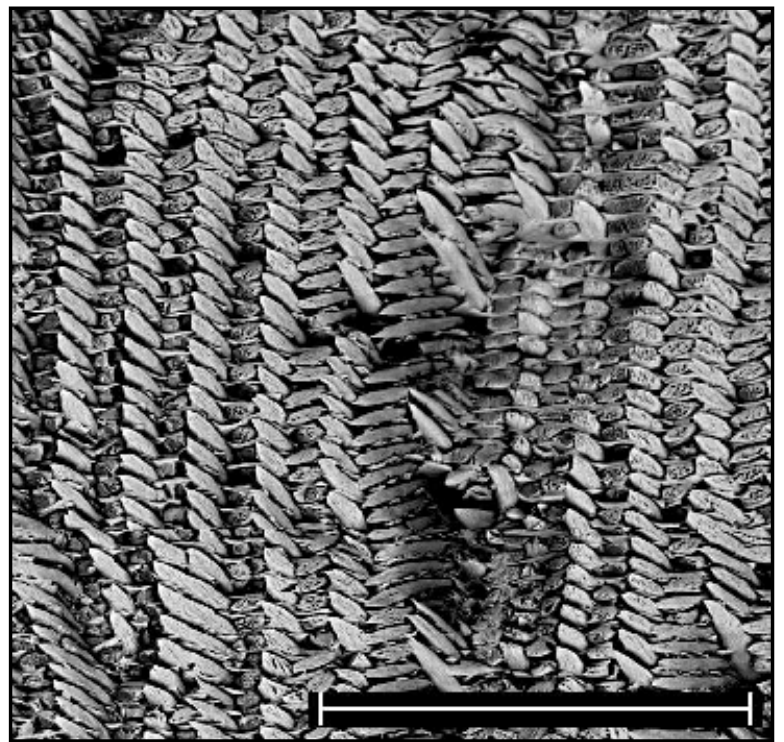

Fig. 2 Irregular enamel structure of an apical diabetes region (bar $50 \mu \mathrm{m}$ )

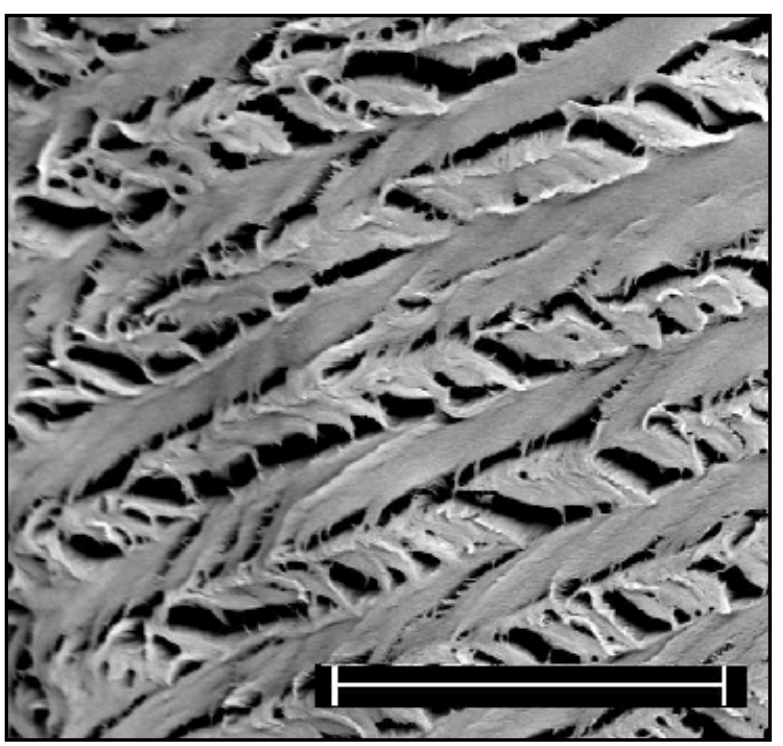

Fig. 4 Irregular enamel structure of an apical diabetes region (bar $20 \mu \mathrm{m}$ ) 